\title{
USO DE NITAZOXANIDA NO TRATAMENTO DE TRICOMONÍASE EM AVES: RELATOS DE CASOS
}

\author{
(Nitazoxanide in the treatment of trichomoniasis in birds: case reports)
}

\begin{abstract}
${ }^{1}$ Sofia Silva La Rocca de Freitas, ${ }^{2}$ Ariam Figueiredo Martinello, ${ }^{2}$ Cecília Haarengl de Souza Braz, ${ }^{2}$ Guilherme Mazocante de Oliveira, ${ }^{2}$ Lenon Silva Lemos de Oliveira, ${ }^{2}$ Maria Eduarda de Quadros Soares, ${ }^{2}$ Líria Queiroz Luz Hirano
\end{abstract}

${ }^{1}$ União Pioneira de Integração Social - UPIS, Brasília. ${ }^{2}$ Universidade de Brasília - UnB, Brasil.

\section{*Correspondência: eduarda.qsoares@gmail.com}

Resumo: Trichomonas sp. é um protozoário flagelado causador da tricomoníase. Este parasito afeta principalmente os tratos digestivo superior e respiratório de aves, com ocorrência comum em espécies das ordens Columbiformes, Falconiformes e Psittaciformes (SILVA, 2017). O objetivo do presente trabalho é relatar três casos resolução da tricomoníase em aves tratadas com nitazoxanida. Foram atendidos no Setor de Animais Silvestres do Hospital Veterinário da Universidade de Brasília, dois espécimes de Caracara plancus e um de Ramphastos toco, jovens e de sexo indeterminado. Ao exame físico, os dois carcarás se apresentavam em estação e resistiram à manipulação, enquanto o tucano se mostrou pouco responsivo e apático. Os animais apresentavam placas caseosas esbranquiçadas em cavidade oral, as quais foram coletadas através de swab estéril e enviadas para exame parasitológico, com confirmação da presença de Trichomonas sp. Na abordagem inicial todos receberam fluidoterapia com ringer lactato (3\% do peso vivo, SC, SID) durante três dias. No primeiro exemplar de carcará, a primeira abordagem terapêutica para tricomoníase foi realizada com metronidazol $50 \mathrm{mg} / \mathrm{mL}(50 \mathrm{mg} / \mathrm{kg}$, VO, SID), porém não se mostrou efetiva, dado que o segundo exame parasitológico apontou a persistência do protozoário. Como segunda abordagem terapêutica foi realizada a administração de nitazoxanida $20 \mathrm{mg} / \mathrm{mL}$ (42mg/kg, VO, BID) durante sete dias, concluindo o tratamento do animal com êxito. O outro exemplar de carcará e o tucano foram tratados unicamente com nitazoxanida $20 \mathrm{mg} / \mathrm{mL}(42 \mathrm{mg} / \mathrm{kg}$, VO, BID) durante sete dias logo após o primeiro resultado positivo para o parasito, com resolução rápida da infestação. As aves permaneceram no hospital para melhor recuperação de escore corporal e, quando consideradas aptas, foram encaminhadas ao CETAS-DF para destinação. A tricomoníase é transmitida de forma direta pelo contato entre os animais sadios e os carreadores, por ingestão de água, alimento e fômites. Dito isto, populações de animais silvestres são extensivamente afetadas devido à alta circulação nos ambientes e o compartilhamento de espaços durante forrageamento. A prevalência de Trichomonas sp. em aves de rapina de vida livre também seria justificada por seus hábitos alimentares devido à predação de Columbiformes, que podem carrear o protozoário sem apresentarem sinais clínicos. Existem relatos de tricomoníase em tucanos, mas são mais escassos. A nitazoxanida possui atividade antimicrobiana de amplo espectro, sendo uma medicação eficaz contra helmintos e protozoários intestinais. Sua ação está relacionada ao bloqueio da reação de transferência de elétrons dependente da enzima piruvato-ferredoxina oxidoredutase, essencial para o metabolismo anaeróbico. Este princípio ativo e seu metabólito ativo tizoxanida são capazes de inibir o crescimento de formas trofozoítas de Trichomonas sp. in vitro. Ainda são escassos estudos acerca do uso da nitazoxanida no tratamento de tricomoníase em aves (EEDIC, 2016), por isso, relatos como o presente são importantes como fonte de informações para opções terapêuticas na medicina de animais silvestres. Nos casos descritos, o uso de nitazoxanida foi eficaz no tratamento de tricomoníase de dois exemplares de carcará e um de tucano, mas ainda carecem trabalhos que demonstram a ação do medicamento no tratamento deste parasito.

Palavras-chave: carcará; protozoário; trichomonas; tucano. 